\title{
Navigating Towards Self-Care: The Catalan Public Patient Portal
}

\author{
Joan Rodon Modol
}

\subsection{Introduction}

This chapter presents the genesis and evolution of the public patient portal called Carpeta Personal de Salut ${ }^{1}$ (CPS) of Catalonia, Spain. Our account of the CPS covers the period 2008 to 2015 . The CPS gives citizens secure and confidential access to their health data (generated in the public health system). The case narrative shows how the installed base was gradually extended with new partners and services aiming to increase the value and usefulness of the infrastructure in order to attract more users. The reminder of the chapter is structured as follows. In the next two sections, we present the Catalan healthcare model and the installed base of IT systems. This is followed by our narrative of the case. Next we discuss the implications of our findings.

\subsection{The Catalan Healthcare Model}

The Spanish National Health System comprises both the Central Government Administration and the autonomous regions. The former is in charge of the (1) health basic principles and general coordination; (2) foreign health affairs and international relations and agreements; and (3) legislation on pharmaceutical products. Each autonomous region is responsible of health planning, public health, and healthcare services management. The Health System of the autonomous region of Catalonia involves four main actors: the Catalan Department of Health (DoH); the CatSalut (the Catalan Health Service); health providers; and citizens. The $\mathrm{DoH}$ is in charge of establishing health policies and maintaining levels of quality in delivery by creating a health plan, determining a healthcare budget, and accrediting

\footnotetext{
${ }^{1}$ Personal Health Folder.

J.R. Modol

ESADE Ramon Llull University, Av. Torreblanca 59, 08172 Sant Cugat del Vallès, Spain

e-mail: joan.rodon@esade.edu
} 
providers. The CatSalut is the public insurer that is responsible for planning, purchasing, and assessing health services according to the needs of the population. The CatSalut establishes service policies in line with the health policies defined by the DoH. The Catalan territory is divided into seven health regions. Each region is structured in turn in health sectors, which bring together the so-called basic health areas formed by neighbourhoods or districts in urban areas, or one or more municipalities in rural areas. The health providers are those organizations that the CatSalut contracts to provide care services. Each health provider has a multiannual contract with the CatSalut that is revised on a yearly basis and includes health objectives, activity, economic amount, rates (pricing), invoicing system, and evaluation system.

The provision of healthcare is done by multiple contracted providers having different ownership: public companies - the Catalan Health Institute (ICS) is the biggest one-, consortia, municipal foundations and private foundations (see Table 11.1). The provision of healthcare is organized into four main levels: primary care; specialized or hospital care; socio-sanitary care; and mental health. Primary care is the gatekeeper and responsible for coordinating the patients' care along the care continuum. Since the primary healthcare reform (in 1985) primary care has evolved from a predominantly curative care model (upon demand from the user population and the work of individual healthcare professionals) to a model that focuses simultaneously on preventive healthcare, curative healthcare, rehabilitative care and the promotion of community health. This transformation was structurally achieved through the creation of basic health areas and the gradual introduction of primary care teams. Nowadays, there are 369 primary care centres, around $77 \%$ of them being managed by the public provider ICS.

Specialized or hospital care acts as a consultant of primary care and is responsible for more complex care. There is a public network of hospitals distributed over the territory following the schemes of population distribution. The model of hospital has changed in recent years, progressing from a traditional model of a more closed centre that provides conventional inpatient care, emergencies and an outpatient department, to a centre with a greater outpatient focus, with significant roles for ambulatory major and minor surgery, day hospital and home hospitalization. Nowadays there are 69 hospitals (the ICS manages 8 of those hospitals). Around $79 \%$ of the specialized care is managed by non-public providers.

Table 11.1 Ownership of healthcare facilities

\begin{tabular}{l|l|l|l|l}
\hline \multirow{2}{*}{ Type of center } & \multicolumn{2}{l|}{ Public } & \multicolumn{2}{l}{ Non-public } \\
\cline { 2 - 5 } & Property (\%) & Management (\%) & Property (\%) & Management (\%) \\
\hline Specialized/hospital care & 25,94 & 21,43 & 74,06 & 78,57 \\
\hline Primary care & 95,40 & 87,72 & 4,60 & 12,28 \\
\hline Mental care & 28,87 & 27,38 & 71,13 & 72,62 \\
\hline Long-term care & 68,63 & 62,75 & 31,37 & 37,25 \\
\hline
\end{tabular}

Source: Catalan Department of Health 


\subsection{The Installed Base of IT Systems}

The multi-provider nature of the Catalan healthcare model had always given providers autonomy in the management of centers and freedom in selecting, building and managing their health IT (HIT) systems. Historically there had been no guidelines regarding the HIT systems that health providers should have in place. So, the Catalan health system traditionally had a completely decentralized governance model for IT. This led to a situation with more than 60 different HIT systems for primary care and hospital care without any kind of integration, and heterogeneity among providers in terms of the level of adoption of HIT.

For instance, in the case of hospital care there are multiple HIT systems supporting different clinical protocols, messages, catalogues, etc., meaning that each provider has to build multiple interfaces for the same purpose (to interact with other providers). Major providers have HIT systems based on SAP. ${ }^{2}$ For instance, ARGOS is a SAP-based HIT developed by IBM that runs in the 8 hospitals of the ICS and some other hospitals.

At the level of primary care, there are several HIT systems (e.g., eCAP, OMI-AP, GO-WIN, SIAP-Win); eCAP is the dominant one. eCAP was developed in 2000 by clinicians of the Catalan Health Institute (ICS). The motives for the development of eCAP were: the existence of three different HIT systems for primary care within ICS; provider lock-ins; and interoperability issues among those HIT systems. More than $80 \%$ of primary care centers run eCAP. Moreover, the Health Plan 2011-2015 (HealthPlan 2011) proposed making available eCAP to all the other providers in 2012 aiming at having a common HIT system for all primary care providers. However, by that time there were multiple versions of eCAP reflecting the diverse rollouts of eCAP in the territory. In addition, eCAP had more than 20 databases and each patient's data were stored in several databases. Further, eCAP had a strong physical architecture meaning that professionals were aware of the server they connected each time they run an application.

\subsubsection{The Shared Electronic Medical Record of Catalonia}

Overall, the multiplicity and heterogeneity of HIT systems, data models and standards, and working processes turned into a problem as the DoH defined efficiency, continuity of care and integrated care as priorities in the successive health plans since early 2000s. The implementation of these priorities required standardizing and sharing information within and across health providers. This motivated the $\mathrm{DoH}$ to build and rollout the Historia Clínica Compartida (HC3), a Shared Electronic Medical Record, in 2008. The purpose was that any healthcare professional could access data about her patients regardless which providers had generated the data. The HC3 interconnected all the electronic health record systems (EHR) of the healthcare providers operating in the Catalan public health system. The HC3 was

\footnotetext{
${ }^{2}$ http://go.sap.com/solution/industry/healthcare.html
} 

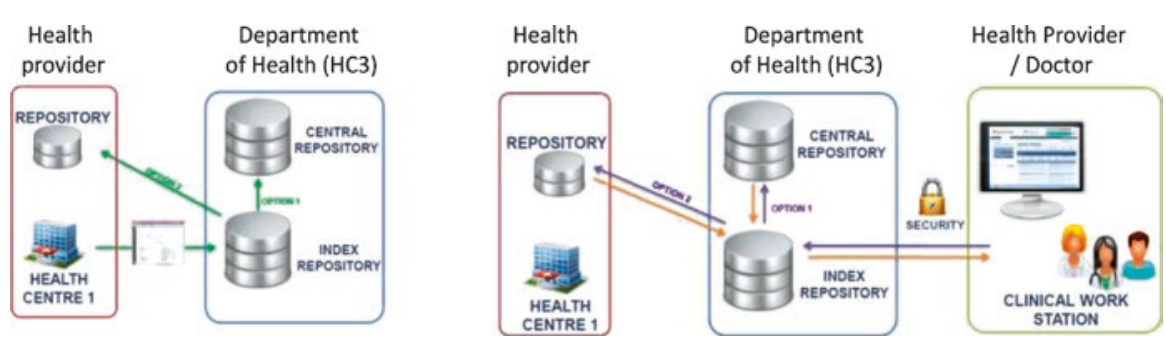

Fig. 11.1 Information management processes of the $\mathrm{HC} 3$

neither conceived as the sum of the EHRs of the health providers nor as a way to replace the existing EHR of providers, but as an infrastructure that would organize the access to health data stored in the EHRs of health providers and in some databases of the DoH (Marimon-Suñol et al. 2010). The HC3 consisted of a central node working either as an index or a repository of documents that would give access to all doctors (through a web browser) to the information coming from the EHRs of the diverse providers (see Fig. 11.1).

The information displayed in the doctors' browser came from (1) health providers: primary care (diagnoses, healthcare reports, immunizations, and chronic patient labels), specialized care, long-term care and mental care (discharge report, emergency reports, specialized outpatient clinic reports), and diagnosis procedures (pathology and laboratory reports, radiology image, imaging diagnosis reports, interventions); and (2) the DoH: medical activity database (diagnoses, procedures), prescribed/dispensed drugs (electronic prescription), and advanced directives. The HC3 provided a set of tools for direct messaging between health professionals to facilitate their cooperation.

The interconnection of healthcare providers' systems to the HC3 was regulated through an agreement between providers and the DoH (AgreementForHC3 2009). That agreement established the commitments of parties as well as the technical requirements. Moreover, the CatSalut promoted providers adoption of HC3 by means of economic incentives (defined in the annual contracts with providers) related with the publishing of documents. By the end of 2011, 96.5\% of primary care centers and $85.5 \%$ of hospital care were connected to HC3 (CatSalutReport 2011).

The HC3 grew with new users, functional requirements (e.g. types of health data, identification codes, interconnection of the HC3 with the Spanish Shared Electronic Medical Record and with the European Patients-Smart Open Services), and technological requirements (e.g. compression of data, new security layers, HL7 messages). Moreover, the Health Plan for the period 2011-2015 (HealthPlan 2011) defined a project, within the line of action number 9 called "Sharing information, transparency, and assessment", to transform the HC3 from a repository of health data into a network of information and services that facilitated the integration of providers. All this involved extending the HC3 with new sources and formats of data, access modes and services, and standardizing the patient trajectory 
Table 11.2 Evolution of $\mathrm{HC} 3$

\begin{tabular}{l|l|l}
\hline & $\begin{array}{l}\text { Repository of health data } \\
(2008-2011)\end{array}$ & Network of information and services (2012-2015) \\
\hline $\begin{array}{l}\text { Source of } \\
\text { data }\end{array}$ & $\begin{array}{l}\text { Repository of health data } \\
\text { from primary care }\end{array}$ & $\begin{array}{l}\text { Repository of health data from primary, hospital, } \\
\text { socio-sanitary and mental care }\end{array}$ \\
\hline $\begin{array}{l}\text { Format of } \\
\text { data }\end{array}$ & $\begin{array}{l}\text { Document-oriented database } \\
\text { (stores PDF documents, or a } \\
\text { link to the document in the } \\
\text { provider EHR) }\end{array}$ & $\begin{array}{l}\text { Structured data about diagnosis, immunizations, } \\
\text { spirometry, patient trajectory, etc. }\end{array}$ \\
\hline Access & Access through web-browser & $\begin{array}{l}\text { Access through web-browser and integration with } \\
\text { clinical work stations }\end{array}$ \\
\hline Services & $\begin{array}{l}\text { Static view of the patient } \\
\text { data }\end{array}$ & $\begin{array}{l}\text { Extension of HC3 with a messaging platform to } \\
\text { include the patient trajectory and the management } \\
\text { of the clinical protocols for the ten chronic } \\
\text { pathologies prioritized in the (HealthPlan 2011) }\end{array}$ \\
\hline
\end{tabular}

and the management of clinical protocols across providers (Carrau et al. 2013) (see Table 11.2).

Overall, although $\mathrm{HC} 3$ respected the installed base of HIT systems, its evolution influenced some of its components. On the one hand, the HealtITPlan (2012) suggested that eCAP (the dominant HIT system at primary care) became the unique system of primary care. First, that would create efficiencies (e.g., any change is implemented once and replicated everywhere; having a unique data model for all the primary care). Second, the strategy of integrated care defined in the HealthPlan (2011) was built around primary care, thus having a unique common system for primary care was supposed to be aligned with the vision of integrated care and continuity of care. On the other hand, in specialized care there are multiple HIT systems. Yet the fact that the major health provider (ICS) runs ARGOS (developed by IBM), and that IBM is a central actor in the definition of the new messaging platform (that extends the HC3) might be catalysts for the reduction of the number of HIT systems in specialized care. Next section presents the story of the Catalan public-oriented portal which was built on the achievements of the HC3.

\section{Method}

Data was collected from three main sources: semi-structured in-depth face-toface interviews (37 interviews), participant observation (the author registered for the CPS on 2011 and has used it intermittently during 2011, 2012, 2013 and 2015; workshop attendance; and informal conversations), and archival data (press documents, reports, meeting minutes, and videos), aiming at data triangulation (Yin 2003). Conducting the interviews was organized in three stages between 2011 and 2015: (1) from March to June 2011 (17 interviews); (2) from March to June 2013 (10 interviews); and (3) from December to October 2015 (10 interviews). 
We identified interviewees by referral from other subjects. All the interviews were recorded and immediately transcribed and analyzed next two the archival data and other observations. In that sense, data collection and analysis took place iteratively.

With the data gathered, we constructed an initial timeline of events for the evolution of the CPS. We then wrote a rich chronological case story that put at the forefront the role of the installed base. We organized the case narrative into three stages covering the period 2008-2015.

\subsection{Case Narrative}

\subsubsection{Phase 1: Genesis and Pilot (2008-2011)}

The Catalan Department of Health (DoH) launched the project of the Carpeta Personal de Salut ${ }^{3}$ (CPS) in 2008 as part of the execution of the Catalan health IT strategic plan for the period 2008-2011 (HealthITPlan 2008). ${ }^{4}$ The leader and sponsor of the CPS was the coordination of Health IT of the DoH. With the CPS they wanted to promote responsibility and participation of citizens in matters of their own health (preventive actions and self-care); to have a secure environment for citizens to interact with health system, providers and professionals; and to improve the health care quality and coordination between different care areas, levels and professionals. Following existing regulations about the information rights and autonomy of the patient (InformationRightsAct 2000; PatientAutonomyAct 2002), the health data displayed in the CPS would come from the HC3 (Cerdà-Calafat et al. 2010). The HC3 was the main source of data of the CPS (see Fig. 11.2). The CPS would be a module of the $\mathrm{HC} 3$, acting as a web-browser based viewer for citizens to the data generated in the public health system.

Another line of action of the health IT strategic plan, related with the development of the CPS, was the diffusion of digital certificates among citizens in order to interact with the health system. Following the regulations about the protection of personal data (DataProtectionAct 1999; DataProtectionDecree 2007), CPS management decided that citizens would use their personal identification code ${ }^{5}$ and a digital certificate to access the CPS. Data transfer would be (https) encrypted with 128-bit

\footnotetext{
${ }^{3}$ Carpeta Personal de Salut means Personal Health Folder.

${ }^{4}$ The HealthITPlan (2008) was part of the Health Plan for the period 2006-2010, which for the first time defined IT as a strategic lever of the health system. The HealthITPlan (2012) defined the project of the CPS as part of the strategic line "Facilitate and orient the access of citizens to information and service for self-care".

${ }^{5}$ The DoH gives each citizen of Catalonia an individual health card which contains data fields such as personal identification code (which corresponds to the code of the insured citizen), the name and surname, the social security affiliation number, type of insured (level of coverage), the expiration data. All these data fields are coded in a magnetic stripe.
} 


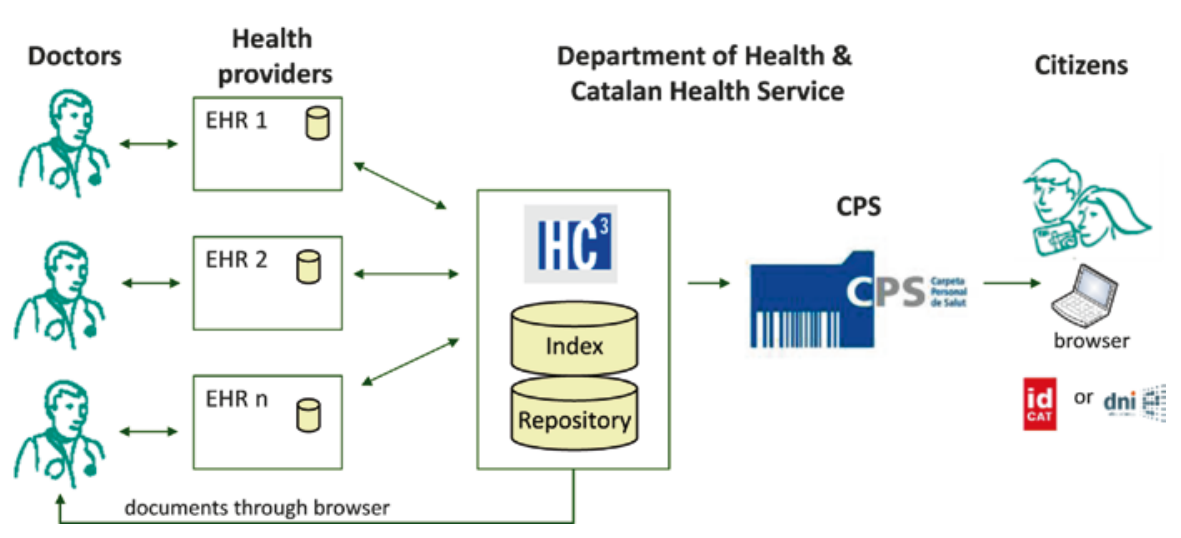

Fig. 11.2 Architecture showing the relation between HC3 and CPS

key. There would be two types of valid digital certificates: the one issued by the Catalan Certification Agency $\left(\mathrm{CATCert}^{6}\right)$ called idCat, and the one embedded in the National Identity Number (DNI electronico). To obtain the first type of digital certificate citizens would have to first fill an online form, next they would have to physically visit a registration agency where their identity would be checked and they would be given a password. Citizens later would use that password to download the digital certificate from the website of the CATCert. In short there would be three actors involved in the registration process: the citizen, the CATCert which would act as a Certificate Authority, and the organization which would accredit the identity of the citizen. During authentication, CPS would check in the database of insured citizens (of the CatSalut) that the personal identification code corresponded with the identity number contained in the digital certificate, and that the citizen had the right to access data.

In 2009, the sponsors of the CPS run a first pilot with a group of 90 citizens working in the health sector of Calella aiming to test the usability, the adequacy of the data, and identify new requirements. The users were employees of the City Council of Calella and of the main health provider operating in the health sector. ${ }^{7}$ Users assessed the CPS satisfactorily: $97 \%$ of users evaluated the CPS as something useful or very useful, with $73 \%$ of them evaluating the navigation through the CPS as good or very good, and $92 \%$ of the users evaluating the language used as appropriate or very appropriate (Saigí et al. 2012). After this pilot, CPS management decided to roll out the CPS on July 2010 with the 21,000 citizens of the health sector of Calella. This release of the CPS included two main types of services: health data from $\mathrm{HC} 3$ (e.g. diagnosis, vaccines, and reports such as ambulatory care, hospital

\footnotetext{
${ }^{6}$ The CATCert is a governmental agency that was set up in 2002 in order to implement and rollout the digital signature in all the Catalan governmental institutions and provide services to those organizations ensuring that the electronic transactions fulfill the legal guarantees.

${ }^{7}$ The name of the provider is the Corporació de Salut del Maresme i la Selva (http://www.salutms.cat).
} 
emergencies, and hospital admission) and access to some administrative services that the Catalan Government already offered (e.g. http://web.gencat.cat/en/tramits/ index.html).

The rollout involved the cooperation and engagement of several local actors in the territory who were close to citizens: the health provider operating in that health sector; the city council that was in charge of communicating to the public; and other local organizations (one of which issued the digital certificates). The leader of CPS qualified such a rollout strategy as "low profile": "we started with this very limited concept of a personal health folder in the sense that it was a collection of documents that were already in the shared electronic medical record [HC3]". The sponsor considered that it was important to adopt a strategy that minimized conflict with professionals since the CPS entailed profound changes in the role and relationships between doctors and patients, and between doctors themselves.

Following this territorial rollout strategy, the CPS was extended to two additional health sectors where the same health provider operated. The CPS was also extended to 1,500 blood donors (from throughout Catalonia). Yet by that time the usage of CPS was still marginal; on December 2011, 88,727 citizens had access to the CPS, but only 365 had accessed it 1,282 times (CatSalutReport 2011).

\subsubsection{Phase 2: Opening the CPS (2012-2013)}

The health IT strategic plan for the period 2012-2015 (HealthITPlan 2012) ${ }^{8}$ defined an strategic line "Deploy a multichannel network to communicate and interact with citizens" involving seven concrete actions on the CPS: (1) boost an strategy that promotes citizens self-care; (2) extend the CPS to all the citizens of Catalonia; (3) increase the functionalities of the CPS; (4) include the medication plan into the CPS; (5) include value-added services into the CPS; (6) promote the access to the CPS through different channels; and (7) promote the diffusion of digital certificates among citizens.

In accordance with these actions, by early 2012 the CPS was extended to other health sectors in Catalonia where other providers operated. Secondly, they built a mobile web app to access the CPS. They also extended the CPS with new reports (e.g., laboratory test results and imaging reports) and new information services from other systems of the DoH (e.g. the medication plan from the electronic prescription system) (see Fig. 11.3). In March 2012, the DoH launched the web-portal Canal Salut, ${ }^{9}$ which provided information to citizens in order to promote healthy lifestyles, strengthen the ability of citizens to make informed decisions about their own health

\footnotetext{
${ }^{8}$ While HealthITPlan (2008) putted the focus on the need to build technical/hard infrastructure, HealthITPlan (2012) changed the focus an emphasized the need for service infrastructure. This change in focus was aligned with two lines of action of the HealthPlan (2011): line of action 2 "A system that is more focused on chronic patients", and line of action 9 "Sharing information, transparency, and assessment".

${ }^{9}$ Canal Salut means Health Channel, http://canalsalut.gencat.cat
} 


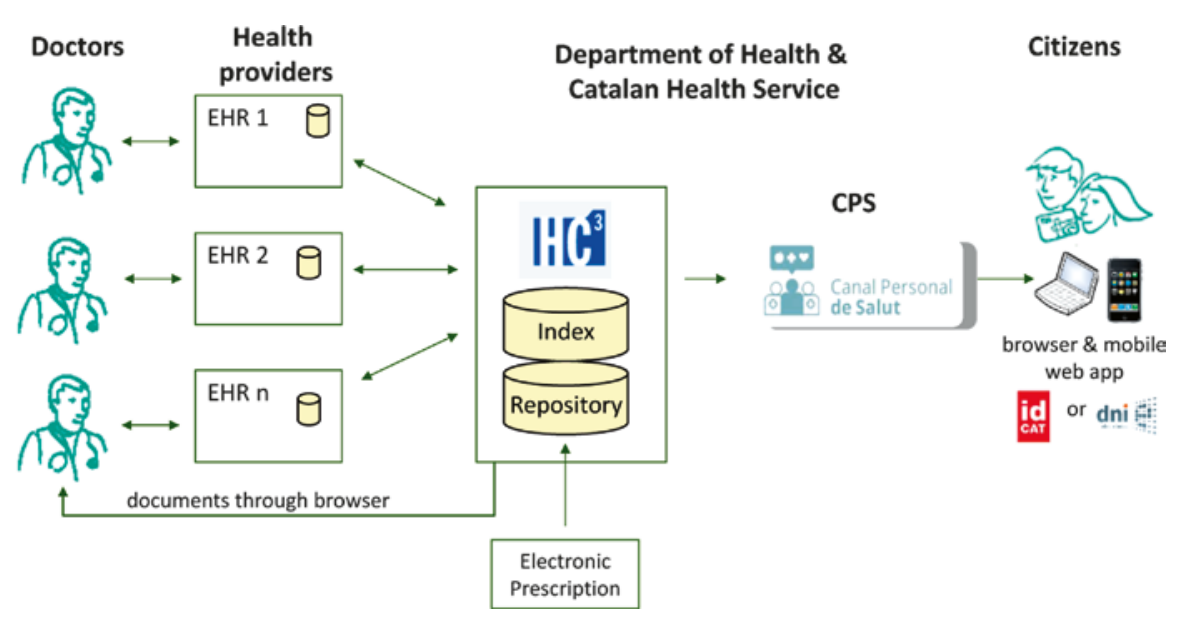

Fig. 11.3 Extension of the CPS architecture

care, and improve citizens' access to health services, among others. By the end of $2012,{ }^{10}$ the DoH announced the deployment of CPS to everyone in Catalonia (about seven million people), and the name of the CPS was changed from Carpeta Personal de Salut (Personal Health Folder) to Canal Personal de Salut (Personal Health Channel) to emphasize the idea of interactivity and communication between patients and professionals.

Until then the CPS had mainly worked as a viewer of the HC3. This was a constraint since the CPS mainly offered content (general reports and health records) to patients but not services. In addressing this constraint, by mid-2012 the CPS managers decided to open CPS to third-party services that were not owned by the DoH. With this opening strategy CPS management aimed to leverage on the installed base of services of third-parties (e.g. health providers, software vendors, pharmaceuticals) and on the latter's capacity to keep innovating on new services. Furthermore, this opening strategy added value to the CPS without requiring the DoH to increase the budget of the CPS. To implement this strategy, TICSalut ${ }^{11}$ set up an interoperability framework that defined the conditions for third-party devices, systems and services to interoperate with CPS (InteropFramework 2012). Companies that wanted patients to access their services through CPS would have to fulfil certain conditions in order to obtain the interoperability recognition. Accordingly, under this interoperability framework, the ownership and control of the services of the CPS started to separate. The DoH would gave up the ownership of the new services

\footnotetext{
${ }^{10} \mathrm{By}$ that time, there was the appointment of a new coordinator of Health IT at the DoH who also became the leader of the CPS.

${ }^{11}$ TICSalut is an agency, constituted in 2006, within the DoH that works to promote the development and use of IT in the field of health, acts as an observatory for new trends, innovation and monitoring of emerging initiatives and provides services for the standardization and accreditation of products.
} 


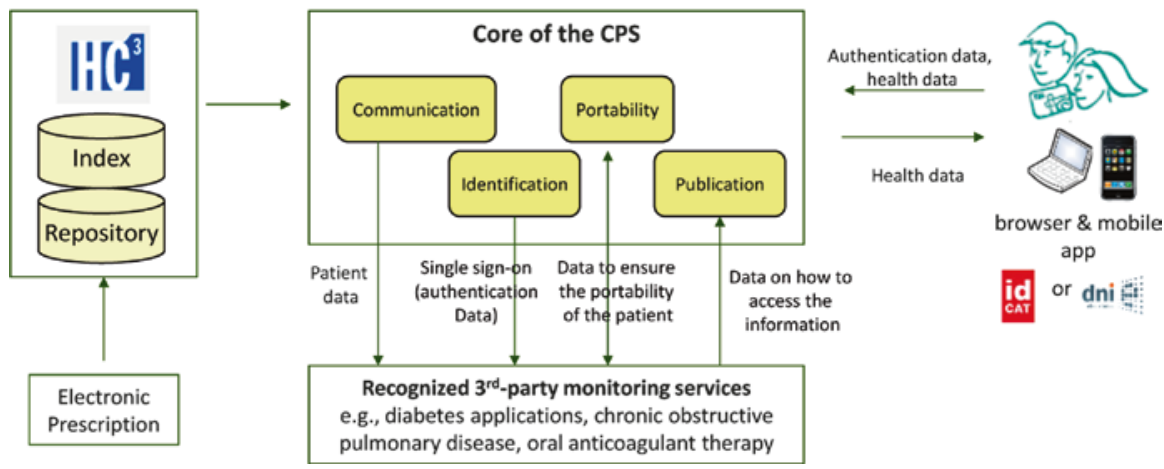

Fig. 11.4 Extension of the CPS to incorporate the interoperability framework

but not their control (e.g., the DoH had the right to decide which new services would be offered).

In the case of systems and services, the interoperability framework consisted of four profiles (see Fig. 11.4): identification (in order to guarantee a single sign-on from the citizen for the CPS and the third-party service); communication (so that third-party services can access relevant patient information stored in HC3); publication (the third-party publishes a set of services that citizens will see in CPS; patients can access those services directly by means of a service embedded in CPS or an URL); and portability (a set of conditions to ensure that personal health data stored by the third-party service can be moved, if the citizen desires, to other third-party services). Each of these profiles defined a set of messages that CPS and the thirdparty services should exchange. With the deployment of the interoperability framework, the DoH would not develop new services but would partner with those third-party providers who offer their services through CPS. The DoH would control the content and the application of the interoperability framework.

The DoH started by targeting firms providing services for monitoring diabetes (in 2012), and the management of chronic obstructive pulmonary disease and oral anticoagulant therapy (in 2013). In the case of the services for monitoring diabetes, CPS management exploited the fact that the ICS was making a tender for the supply of test strips for the following years. ${ }^{12}$ The DoH asked the ICS to include compliance with the interoperability framework as a bid condition. From that moment, the interoperability framework became an obligatory passage point for providers of devices for the treatment of diabetes who wanted to access the public health system. These services for tele-monitoring diabetes provided three main types of functionalities: patients recording and tracking of blood glucose readings and other informa-

\footnotetext{
${ }^{12}$ The providers of test strips - usually pharmaceutical companies such as Sanofi, Roche - also provide the other devices for the treatment and control of the disease - e.g. glucometers, insulin pens, and the software application for patient to self-monitor their disease.
} 
tion, health professionals monitoring the status of patients, and information exchange between patients and health professionals. Yet the fact that these services could be accessed through the CPS did not add additional value because the CPS was merely an additional channel to access those monitoring applications. Moreover, neither health professionals nor patients received any incentive to go through the CPS. So the fact that these three types of services got the interoperability recognition, did not mean that patients and health professional would immediately abandon their direct access to those services in favor of the CPS.

For providers of those services it was a way to stay close to the DoH. Moreover, CPS management realized that the providers would not easily update their services to new releases of the CPS' APIs. One of those providers argued that they had already done an effort to adapt their application to the CPS for the first time, but they could not keep the pace of updates required by the CPS because decisions about service changes were not made in the local office in Catalonia, but in the headquarters office which was abroad. In short, the CPS was not able to revert the existing practices of the health professionals, diabetes patients, and providers of diabetes monitoring services, and the relationships between health professionals and those providers.

\subsubsection{Phase 3: Scaling the CPS (2014-2015)}

By mid-2013 the adoption level of the CPS was still unsatisfactory - e.g., until May 2013 only 4,664 citizens had accessed the CPS since its inception; on average there were less than 1,000 accesses per month; reports and diagnoses were the top searched information services (Gallego 2013). CPS management considered that its low rate of adoption and use was due to the lack of use of digital certificates among citizens and the associated registration and authentication processes. These processes were cumbersome and complicated for citizens, particularly, taking into account that some health providers (e.g., ICS) already offered online services for patients (e.g., booking appointments) with much simpler authentication procedures (e.g., code of the citizen's health card). However, the CPS' registration and authentication processes had been implemented following the recommendations of the Catalan Data Protection Authority (APDCat ${ }^{13}$ ) in 2009. By mid-2012 CPS management asked again the APDCat about the need for a digital certificate. This time the APDCat reinterpreted the need for a digital certificate and suggested that a username and password were sufficient (ElectronicDataAccess 2012). So, removing the digital certificate would simplify the registration and authentication processes and this in turn, would make the CPS more attractive for citizens.

\footnotetext{
${ }^{13}$ The APDCat was created in 2002, and its Statute regulated in 2003. It is an autonomous and independent authority whose competences in the public sector data are registration, control, inspection, sanction and resolution, and also the adoption of proposals and instructions. http:// www.apd.cat/en
} 
The changes to the registration and authentication processes were as follows. First, registration would take place at the primary care center of the citizen, where she would have to physically visit to request the access to the CPS. At the primary care center they would check the identity of the citizen through national identify number and the identification code of individual health card, and the citizen would sign an authorization form. Then the citizen would receive an SMS with a PIN code that she would use in the registration process and an email with a link to complete the registration process. In this last step of the registration process, the citizen would choose an 8-digit password. The access to the CPS would take place through the personal identification code plus the national identity number plus the 8-digit password (so there was no need for a digital certificate). Second, citizens' usernames and passwords would be managed by the CatSalut; the CATCert would not be involved in the registration and authentication process.

On October 2014, a pilot was launched in 33 primary care areas. As a result of the positive outcomes of the pilot, ${ }^{14}$ on May 2015 they started the deployment of the new registration and authentication processes to the rest of primary care areas of Catalonia. On August 2015 more than 25,000 citizens had accessed the CPS (Solans 2015).

In parallel, the CPS was renamed again from Canal Personal de Salut (Personal Health Channel) to Cat@Salut La Meva Salut (Cat@Salut My Health). This change aimed to increase the involvement of citizens and strengthen its diffusion, use and awareness. Accordingly, the user interface of the CPS was also adapted so that the access to data was simpler and more intuitive.

Within the context of the HealthITPlan (2012) the DoH created in 2013 a working group that defined a non-face to face care model for the Catalan health system (NonF2FCareModel 2014). The model, which put the CPS at its core, included the functional requirements, the agents and the interactions among agents, the contents, and the communication channels. The goal was to transform the CPS into a dynamic and proactive environment rather than a passive one. This required integrating nonface to face care into the existing clinical working stations, and giving recognition to the non-face to face activity of health professionals as part of their duties. One of the services defined by the non-face to face care model was eConsultation (a nonface-to-face, secure consultation service between citizens and health professionals). With eConsultation, citizens can send (through the CPS) at any time a request to the health professional (doctor or nurse), receive email notifications when the professional responds the request, check the response at the CPS, and see a record of all the queries. This service is integrated with the clinical workstation of professionals. This service has been integrated into the CPS and is being piloted at nine primary care centers of Barcelona, which are operated by three health providers ${ }^{15}$ running the eCAP workstation, from July 2015 to October 2015. Moreover, three additional services of the ICS got the interoperability recognition (e.g., online booking appointment, change of doctor, international vaccination).

\footnotetext{
${ }^{14}$ Monthly accesses more than tripled (Solans 2015).

${ }^{15}$ The three health providers are ICS, PAMEM and CAPSE.
} 
On February 2014, the TICSalut, commissioned by the DoH and the Department of Social Welfare and Family, collaborated with the mHealth Competence Center of the Mobile World Capital Barcelona ${ }^{16}$ in the development of the Mobility Master Plan for Health (mHealthPlan 2015). The goal of the mHealthPlan (2015), which the DoH approved on February 2015, was to boost the mobility of health and social services as a lever to improve the health and welfare of people and contribute to the sustainability of the system. The mHealthPlan (2015) identified the lines of action and projects of the HealthPlan (HealthPlan 2011) and the non-face to face care model (NonF2FCareModel 2014) that could incorporate mobility.

As part of the implementation of the mHealthPlan (2015), the TICSalut worked on a health apps marketplace ${ }^{17}$ that would match the demand (the public health system, patients and rest of citizens, social and health professionals) and supply (health and social care providers, IT vendors, pharmaceutical companies, insurance companies, and medical equipment vendors) of health and social services. A core component of the marketplace would be the accreditation process which aimed at generating trustworthy apps through a quality certificate. The accreditation process assesses four main aspects of apps: (1) design and usability (assessment of the user experience); (2) content and functionality (assessment of the quality and utility of content); (3) confidentiality and security of data (assessment of the management and processing of data); and (4) technological requirements (assessment of the reliability and adaptability requirements).

The accreditation process comprises six steps: (1) an app developer requests a accreditation for an app; (2) the developer does a self-assessment of the app; (3) if the app meets a minimum criteria then the developer can ask to provisionally include it in the marketplace (with the status "pending accreditation"); (4) an accreditation committee does a complete and detailed assessment of the app; (5) if the app passes this assessment it gets the quality certificate; and (6) the app is finally published in the marketplace as accredited; the marketplace acts as a portal with information about health apps accredited and redirects users to the corresponding Android and/ or iOS market in order to download the app.

Initially they conceived three main types of apps to be prescribed by health and social care professionals: core apps (public-owned apps that exchange data with existing systems of the DoH); non-core apps having the exchange capacity (publicly or privately owned apps that exchange data with the CPS); and non-core apps not having the exchange capacity (privately owned apps that do not exchange data with the CPS).

From mid-2015 TICSalut started working on the design of another core architectural component of the marketplace: the Digital Health Platform (see Fig. 11.5).

\footnotetext{
${ }^{16}$ The mission of the mHealth Competence Center is to promote the improvement of the welfare and health of citizens by personalizing services based on mobile technology. The director of the mHealth Competence Center is the former executive president of TICSalut.

${ }^{17} \mathrm{By}$ the end of 2013 the TICSalut started conceptualizing a marketplace of health apps with different degrees of certification and validation where patients could find apps recommended by doctors (RepTICSalut 2013).
} 


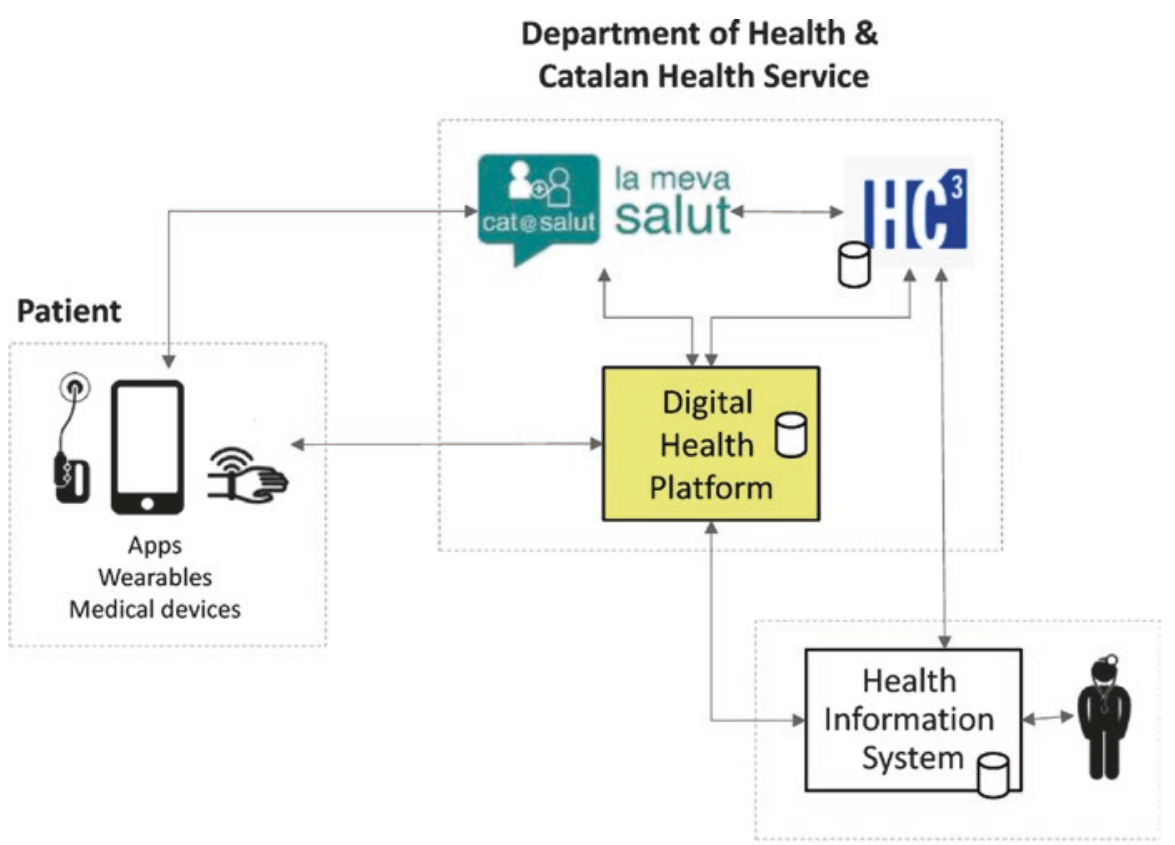

Health Provider \& Doctor

Fig. 11.5 Relationship between the Digital Health Platform and other components

Those apps (and later wearables and medical devices) that are accredited will be allowed to store and/or retrieve information from the Digital Health Platform. So the Digital Health Platform will act as a repository of patient-generated health data and in turn, it be interoperable with the CPS, HC3 and/or health information systems of health providers. Patients will access the content of the Digital Health Platform through the CPS. In other words, the Digital Health Platform will give the public health system access to health data generated by patients outside the public health system.

\subsection{Analysis and Discussion}

Our account has shown how the CPS was built on an installed base. It started as a web-browser viewer of a subset of citizens' health data stored in the systems of the public health system, and has gradually turned into an information infrastructure as new relations with other systems, services, actors, regulations, practices, and so on, have been established. Table 11.3 summarizes the evolution of the CPS according to several dimensions (goal, users, services, authentication mode, access mode, regulations) for each of the three phases. 


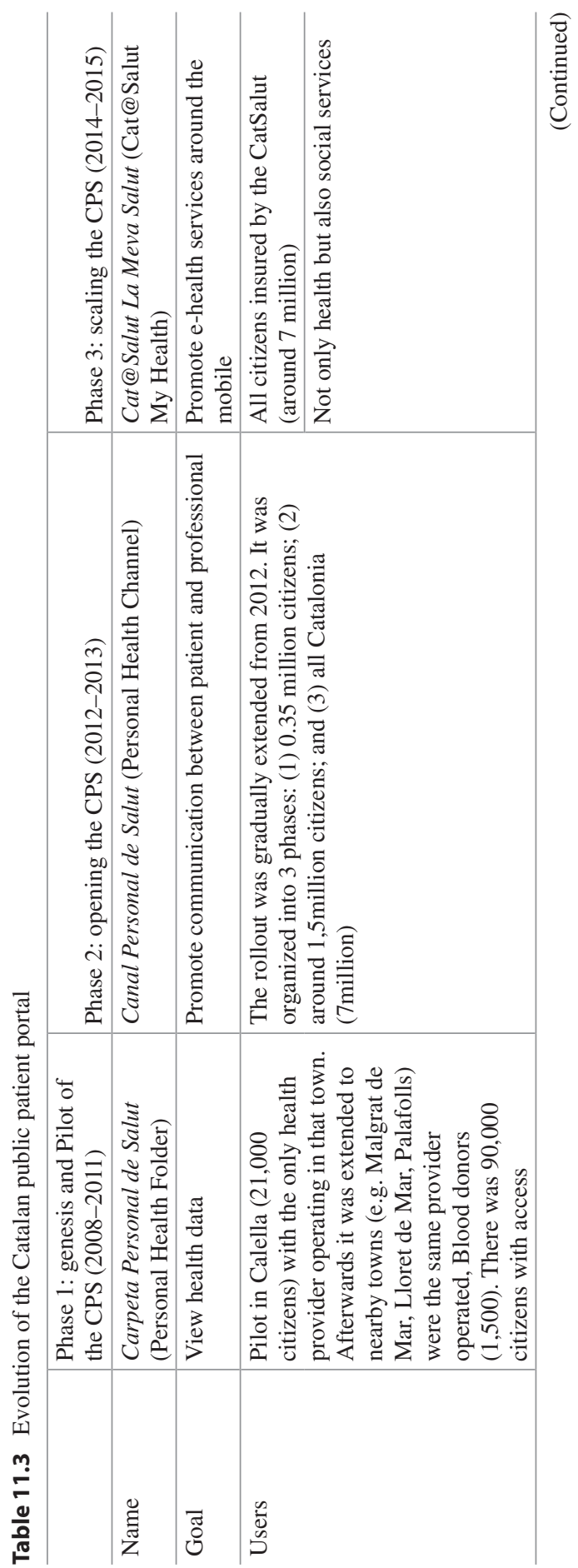




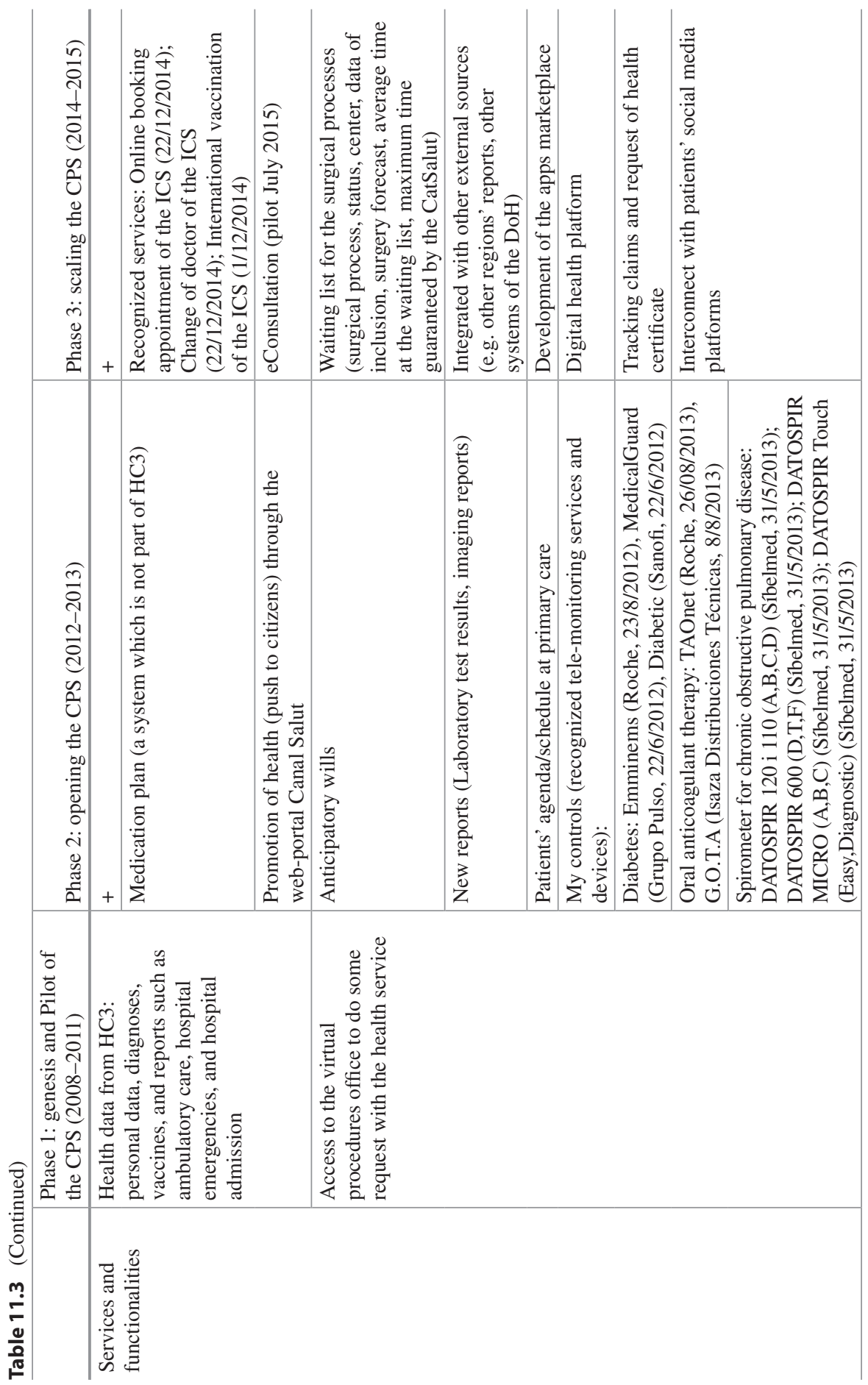




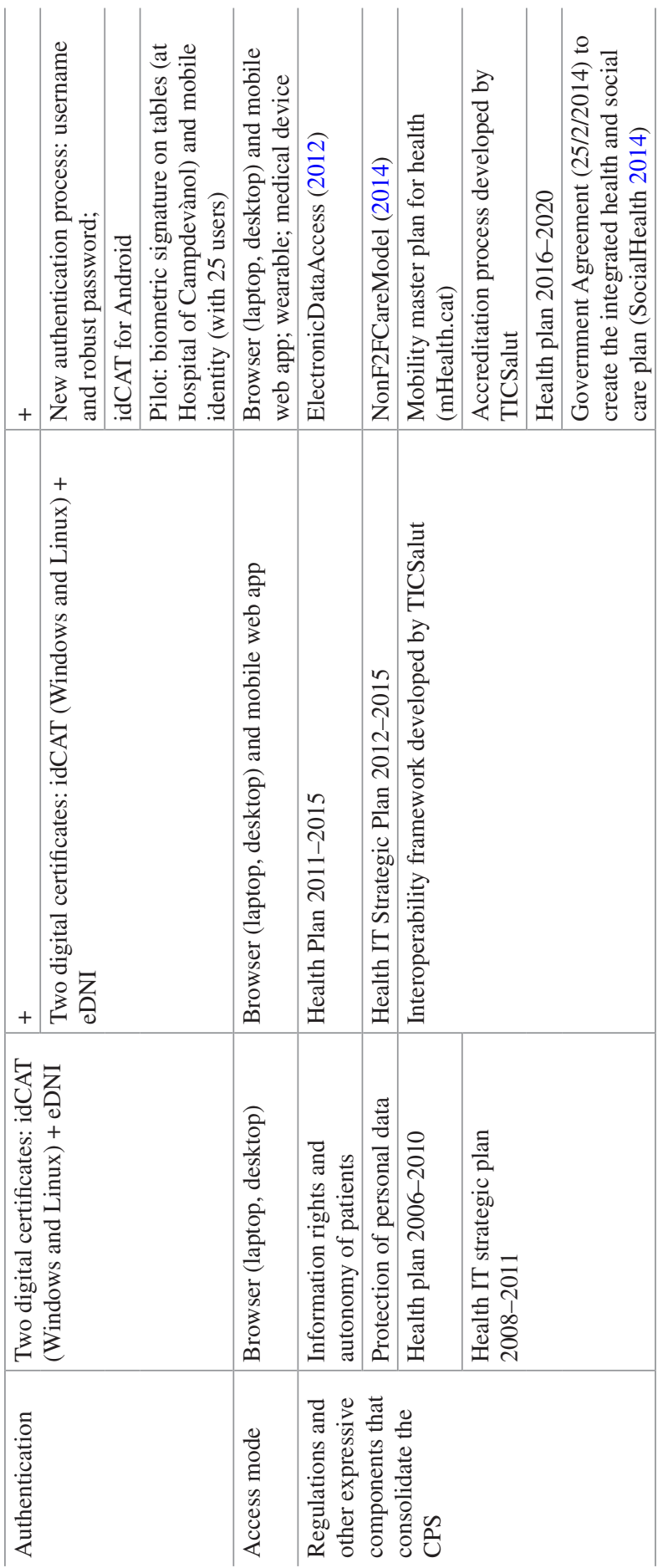


The underlying vision for the building of the CPS has been the idea of self-care and preventive care - i.e., that citizens become more autonomous, responsible and participative in matters concerning their own health. The realization of this vision requires reconfiguring multiple of the existing relationships and the creation of new ones. For instance, since patients will have more information about their own health, their relation with professionals, who are used to have control over the access to the patients' data, will probably change; the relationship between patient and the government is expected to become less paternalistic; the responsibilities boundaries among professionals will most likely shift; and since the CPS will become a new channel for the provision of health services, the public administration will have to reconsider the payment criteria for those services to health professionals and providers.

Accordingly, the effects of realizing this vision are multiple and complex, and beyond the control of any single actor in the health system. For the sponsors of the CPS that meant that they had to engage with indeterminacy and uncertainty, and with multiple possible alternatives. Furthermore, since many of the services could not be specified in advance, their decisions and choices had to be exploratory and adaptable. At the beginning of the project, the sponsors of the CPS took refugee into something known and safe; they decided to tie the CPS' architecture, project organization and development team, and budget to the ones of the Public Shared Electronic Medical Record (HC3). So the CPS started simple, without a big architectural blueprint and complex anticipatory design; the CPS was launched as a webbrowser viewer (a module) of the HC3. Since then the CPS has gradually grown in terms of users and services.

A catalyst for that growth has been the building of specific gateways that interconnect the existing socio-technical components with new ones. For instance, the choice of authentication and registration procedures in which CPS' sponsors interpreted existing regulations in a way that maximized the security and confidentiality and by doing so, avoided opposition of professionals who were concerned about it and stimulated adoption from citizens; the interoperability framework, the app accreditation process, and the Digital Health Platform.

Those gateways have encouraged certain effects. First, the interoperability framework and the app accreditation process, for instance, have constituted the base on top of which third-parties can develop new services which add value to existing patients as well as attract new ones to the CPS. Another effect of these two gateways is the changing role of the public administration (DoH and CatSalut) in the provision of certain services. For instance, the DoH does not own those new services but accredits them; in that respect, the public administration keeps the control over the kind of services offered through the CPS. Likewise, with the building of the Digital Health Platform, they are able to leverage the potential of patient-generated health data to grow the existing infrastructure and at the same time, that opens new opportunities for both sides: app developers as well as the public health system.

Overall, this chapter suggests that in order to cope with the conditions of indeterminacy and uncertainty characterizing the building of patient-oriented information infrastructures, designs must always be incomplete, open and connectable so as to be able to respond to new possibilities. 
Acknowledgements This research was funded by the program "Internacionalització de la Recerca dels grups de recerca de la URL, un programa impulsat per la Universitat Ramon Llull amb la col laboració de l'Obra Social 'la Caixa”.

\section{References}

AgreementForHC3. Conveni tipus per implantar la Història Clínica Compartida a Catalunya (HCCC), Department of Health, Catalan Government. 2009.

Carrau E, Labordena MJ, González M. La Historia Clínica Compartida de Cataluña. Soc Esp Inform Salud. 2013;97:8-11.

CatSalutReport. Memòria del CatSalut 2011, Generalitat de Catalunya, Departament de Salut. 2011.

Cerdà-Calafat I, Continente-Gonzalo M, García-López C, Guanyabens-Calvet J. Carpeta personal de salud. Med Clín. 2010;134(1):63-6.

DataProtectionAct. Ley Orgánica 15/1999, de 13 de diciembre, de protección de datos de carácter personal, BOE n 298 of December 14th 1999, Spanish Government. 1999.

DataProtectionDecree. Real Decreto 1720/2007, de 21 de diciembre, por el que se aprueba el Reglamento de desarrollo de la Ley Orgánica 15/1999, de protección de datos, BOE n 17 of January 19th 2008, Spanish Government. 2007

ElectronicDataAccess. CNS 29/2012: Accés electrònic a dades de salut sense certificat electronic", Autoritat Catalana de Protecció de Dades, viewed 1 December 2015. 2012. http://www.apd.cat/ media/dictamen/ca_461.pdf.

Gallego C. iSalut: Sessió tècnica. Pla de Salut de Catalunya 2011-15. El model d'atenció a la complexitat: Gestió Clínica del PCC i MACA, viewed 1 December 2015. 2013. http://www. uch.cat/index.php?md=documents\&id=6513\&lg=cat.

HealthITPlan. Pla Estratègic SITIC per a l'Àmbit de la Salut a Catalunya 2008-2011, Catalan Department of Health. 2008.

HealthITPlan. Pla Estratègic SITIC per a l'Àmbit de la Salut a Catalunya 2012-2015, Catalan Department of Health. 2012.

HealthPlan. Health plan for Catalonia 2011-2015, Generalitat de Catalunya. Department of Health. 2011, Catalan Ministry of Health, http://salutweb.gencat.cat/ca/el_departament/ pla_de_salut_2011_2015/.

InformationRightsAct. Llei 21/2000, de 29 de desembre, sobre els drets d'informació concernent la salut i l'autonomia del pacient, i la documentació clínica, DOGC n 3303 of January 11th 2001, Catalan Government. 2000.

InteropFramework. Marc d'interoperabilitat - Carpeta Personal de Salut. Oficina d'Estàndars i Interoperabilitat (OFSTI), Generalitat de Catalunya, viewed 1 December 2015. 2012. http:// www.gencat.cat/salut/ticsalut/html/ca/dir3613/marcinteroperabilitatv1_6.pdf.

Marimon-Suñol S, Rovira-Barberà M, Acedo-Anta M, Nozal-Baldajos MA, Guanyabens-Calvet J. Historia Clinica Compartida en Cataluña. Med Clin. 2010;134(1):45-8.

mHealthPlan. Pla Mestre de Mobilitat (mHealth.Cat), Catalan Department of Health. 2015.

NonF2FCareModel 2014, Model d'atenció no presencial en el sistema sanitari de Catalunya 2013 16, Catalan Department of Health

PatientAutonomyAct. Ley 41/2002, de 14 de noviembre, básica reguladora de la autonomía del paciente y de derechos y obligaciones en materia de información y documentación clínica, BOE $\mathrm{n}^{\circ} 274$ of November 15th 2002, Spanish Government. 2002.

RepTICSalut. Report 2013, viewed 1 December 2015. 2013. http://www.ticsalut.cat/media/ upload//arxius/ticSalt2013ANG.pdf.

Saigí F, Cerdà-Calafat I, Guanyabens-Calvet J, Carrau E. Los registros de salud personal: El caso de la Carpeta Personal de Salud. Gac Sanit. 2012;26(6):582-4.

SocialHealth. Agreement GOV /28/2014 of February 25th, to create the Integrated Health and Social Care Plan (PIAISS), viewed 1 December 2015. 2014. http://www.gencat.cat/salut/botss/ $\mathrm{html} / \mathrm{ca} / \mathrm{dir} 3609 /$ doc35966.html. 
Solans O. HC3 i La Meva Salut - D'Un repositori d'informació a un instrument estratègic dins del model d'atenció integrada centrat en les persones, viewed 1 December 2015. 2015. http://jornadestic.aificc.cat/storage/presentacions-taules/04-La-meva-salut.pdf.

Yin RK. Case study research: design and methods. Thousand Oaks: Sage; 2003.

Open Access This chapter is distributed under the terms of the Creative Commons AttributionNonCommercial 2.5 International License (http://creativecommons.org/licenses/by-nc/2.5/), which permits any noncommercial use, duplication, adaptation, distribution and reproduction in any medium or format, as long as you give appropriate credit to the original author(s) and the source, provide a link to the Creative Commons license and indicate if changes were made.

The images or other third party material in this chapter are included in the chapter's Creative Commons license, unless indicated otherwise in a credit line to the material. If material is not included in the chapter's Creative Commons license and your intended use is not permitted by statutory regulation or exceeds the permitted use, you will need to obtain permission directly from the copyright holder. 